\title{
PW01-030 - Pulmonary manifestations of FMF
}

\author{
AV Sargsyan ${ }^{1}$, AR Davtyan ${ }^{2}$, YS Sargsyan ${ }^{3 *}$ \\ From 7th Congress of International Society of Systemic Auto-Inflammatory Diseases (ISSAID) \\ Lausanne, Switerland. 22-26 May 2013
}

\section{Introduction}

Familial Mediterranean Fever (FMF) is an autoinflammatory disease. It is associated with vasculitis, pulmonary hemorrhage, infiltrates, and pulmonary hypertension due to amyloidosis. These complications however have been reported only rarely.

\section{Objectives}

The aim of our study was to investigate pulmonary consequences of FMF.

\section{Methods}

The study cohort involved 155 FMF patients (male/female $87 / 68$ ). Mean age was $33,6 \pm 11,8$ years in the patients group without renal amyloidosis ( 45 men, 35 women, $\mathrm{n}=80$ ) and $37,8 \pm 7,4$ years in the patients group with amyloidosis (42 men, 33 women, $n=75$ ). All the patients had symptoms related to the respiratory system, such as pleuritic chest pain with or without cough, dyspnea, chest tightness and frequent pneumonias. 28 patients had a history of tobacco use. Most of the patients (122) had M694V mutation, and the rest had other mutations. All the patients were on colchicine treatment at the time of the study with the exception of 2 hemodialysis patients. Laboratory tests, including CRP, SAA and capillary blood gases, ECG and chest X-ray were carried out on all the patients. 50 patients underwent Doppler echocardiography and 25 HRCT scan of the chest.

\section{Results}

Mean C-reactive protein (CRP) and serum amyloid-A (SAA) were $17.74 \pm 13.74 \mathrm{mg} / \mathrm{L}$ vs $11,88 \pm 13.79 \mathrm{mg} / \mathrm{L}$ and $33 \pm 66.6 \mathrm{mg} / \mathrm{L}$ vs $5.25 \pm 4,45 \mathrm{mg} / \mathrm{L}$, respectively, and significantly higher in the patients group with renal amyloidosis than the mean values of the patients group without amyloidosis $(\mathrm{P}<0,000)$. Blood gases values $($ mean $\pm \mathrm{SD})$ were

\footnotetext{
${ }_{3}^{3}$ General Medicine Student, Yerevan State Medical University, Yerevan, Armenia

Full list of author information is available at the end of the article
}

within normal ranges in patients without amyloidosis, and were slightly decreased in amyloidosis patients group $\left(\mathrm{PO}_{2} 83.6 \pm 8.95 \mathrm{~mm} \mathrm{Hg}, \mathrm{PCO}_{2} 39.4 \pm 3.6 \mathrm{mmHg}, \mathrm{O}_{2} \mathrm{Sat}\right.$ $94.6 \pm 3.38 \%$ vs. $\mathrm{PO}_{2} 74 \pm 11.36 \mathrm{~mm} \mathrm{Hg}, \mathrm{PCO}_{2} 35.3 \pm 4.5 \mathrm{~mm}$ $\left.\mathrm{Hg}, \mathrm{O}_{2} \mathrm{Sat} 90.1 \pm 10.26 \%, \mathrm{P}<0.000\right)$. Infiltrates, ground-glass opacities, reticulonodular pattern, pleural effusion and pleural thickening, lymphadenopathy, dilatation and hypertrophy of right ventricle and increased pulmonary artery systolic pressure were more frequent findings in the patients group with amyloidosis than in the group without it, though in the group without amyloidosis they occurred as well.

\section{Conclusion}

Our results suggest that patients with FMF and amyloidosis tend to have hypoxemia. The latter could contribute to pulmonary complications in FMF patients. On the other hand, it is possible that FMF patients without renal amyloidosis experience pulmonary manifestations and develop pulmonary complications. Respiratory symptoms in FMF patients without renal amyloidosis probably result from ongoing inflammation and early vascular alteration. Hypoxemia is a sign of advanced disease.

\section{Disclosure of interest}

A. Sargsyan Consultant for: clinical and lab tests, A. Davtyan Consultant for: lab tests, Y. Sargsyan Consultant for: biochemical tests and statistics.

\section{Authors' details \\ ${ }^{1}$ Internal Medicine, Yerevan State Medical University, Yerevan, Armenia. ${ }^{2}$ ArtLab Diagnostic Center, Artashat, Armenia. ${ }^{3}$ General Medicine Student, Yerevan State Medical University, Yerevan, Armenia.}

Published: 8 November 2013

doi:10.1186/1546-0096-11-S1-A83

Cite this article as: Sargsyan et al:: PW01-030 - Pulmonary

manifestations of FMF. Pediatric Rheumatology 2013 11(Suppl 1):A83. 